\title{
Inconsistent genetic structure among members of a multitrophic system: did bruchid parasitoids (Horismenus spp.) escape the effects of bean domestication?
}

\author{
S. Laurin-Lemay ${ }^{1}$, B. Angers ${ }^{1}$, B. Benrey ${ }^{2 *}$ and J. Brodeur ${ }^{1}$ \\ ${ }^{1}$ Department of Biological Sciences, Université de Montréal, CP 6128, \\ Succursale Centre-Ville, Montréal, Québec, Canada H3C 3J7: ${ }^{2}$ Laboratoire \\ d'Entomologie Évolutive, Université de Neuchâtel, 11 rue Emile-Argand, CP \\ 158, CH-2009, Neuchâtel, Switzerland
}

\begin{abstract}
Anthropogenic range expansion and cultural practices have modified the distribution, abundance and genetic diversity of domesticated organisms, thereby altering multitrophic assemblages through space and time. The putative Mesoamerican domestication centre of the common bean, Phaseolus vulgaris L., in Mexico allows investigating the effects of plant domestication on the genetic structure of members of a multitrophic system. The aim of this study was to compare the evolutionary history of Horismenus parasitoids (Hymenoptera: Eulophidae) to those of their bruchid beetle hosts (Coleoptera: Bruchidae) and their domesticated host plant (P. vulgaris), in the context of traditional agriculture in Mexico. We analyzed the population genetic structure of four Horismenus species in Mexico using mitochondrial COI haplotype data. The two most abundant parasitoid species were Horismenus depressus and Horismenus missouriensis. Horismenus missouriensis were infected by Wolbachia endosymbionts and had little to no population differentiation $\left(F_{\mathrm{ST}}=0.06\right)$. We suspect the mitochondrial history of H. missouriensis to be blurred by Wolbachia, because differentiation among infected vs. non-infected individuals exists $\left(F_{\mathrm{ST}}=0.11\right)$. Populations of $H$. depressus were found to be highly differentiated $\left(F_{\mathrm{ST}}=0.34\right)$, but the genetic structuring could not be explained by tested spatial components. We then compared the genetic structure observed in this parasitoid species to previously published studies on bruchid beetles and their host plants. Despite extensive human-mediated migration and likely population homogenization of its two Acanthoscelides bruchid beetle hosts, $H$. depressus populations are structured like its host plant, by a recent dispersal from a diverse ancestral gene pool. Distinct evolutionary dynamics may explain inconsistent patterns among trophic levels. Parasitoids likely migrate from wild bean populations and are poorly adapted to bean storage conditions similar to their bruchid beetle hosts. Integrating several trophic levels to the study of evolutionary history has proven to be fruitful in detecting different ecological responses to human-mediated disturbances and host parasite interactions.
\end{abstract}

\footnotetext{
*Author for correspondence

Fax: +41327183001

E-mail: betty.benrey@unine.ch
} 
Keywords: Wolbachia, comparative phylogeography, human-mediated migration, plant domestication, multitrophic system, parasitoids

(Accepted 28 June 2012; First published online 4 October 2012)

\section{Introduction}

Interactions among community members are important in creating the selective pressures that drive the evolution of natural and human-modified ecosystems (Tscharntke \& Hawkins, 2002). Comparative studies using crops and their wild relatives have revealed that trophic interactions among plants, herbivores and their natural enemies can be altered by selection of plant attributes during the domestication process (Macfadyen \& Bohan, 2010). Anthropogenic range expansion and cultural practices have modified the distribution, abundance and genetic diversity of domesticated organisms (Doebley et al., 2006), thereby altering multitrophic assemblages through space and time (Macfadyen \& Bohan, 2010). Microorganisms associated with members of a biological system represent additional layers of interactions and are strongly linked to the evolutionary outcome of multitrophic assemblages (Colwell et al., 1996).

Strategies for conservation and plant breeding sometimes consider the use of the genetic diversity of wildweedy-domesticated complexes to improve plant productivity by maintaining the genetic diversity of natural enemies. The study of the genetic structure of pests and their natural enemies can infer recent and ancient events that have shaped the evolution of multitrophic assemblages and the evolutionary consequences of plant domestication on an ecosystem.

The putative Mesoamerican domestication centre of the common bean, Phaseolus vulgaris L., is in a region of Mexico between the Transverse Neovolcanic Axis to the south and the southern edges of the Sierra Madre Occidental and Altiplano to the north (Kwak et al., 2009). It provides an ideal system to investigate the effects of plant domestication on the genetic structure of members of a multitrophic system. Humanmediated migration has been identified as an important evolutionary factor influencing the genetic structure of the bean plants and their associated beetle populations (GonzalezRodriguez et al., 2002; Papa \& Gepts, 2003; Alvarez et al., 2007; Kwak \& Gepts, 2009; Restoux et al., 2010). In the present study, we examined the evolutionary history of a higher trophic level, the parasitoids. We compared these results to those from the plant and herbivorous hosts to determine if population genetic structures are congruent across trophic levels. We predicted that because parasitoids complete their development within the beetle host, the genetic structure of the host and the parasitoid would be similar or equally influenced by humanmediated migration. The intracellular endosymbiont alphaproteobacteria Wolbachia is commonly found in numerous arthropod species (Hilgenboecker et al., 2008). Thus, as a secondary hypothesis, we predicted a bias in the genetic structure of parasitoid populations when infected by Wolbachia due to both the hitchhiking effect of maternally inherited mtDNA haplotypes and the reproductive manipulation strategies used by the bacteria to enhance and spread infection in host populations.

\section{The multitrophic system}

Beans (Leguminosae: Phaseolus spp.) are the most important grain legumes for direct human consumption in the world (Broughton et al., 2003). Common beans, Phaseolus vulgaris L., are the primary source of protein in Mexico, with $67 \%$ of the crop being produced on small farms $(<5$ ha) (Broughton et al., 2003). Common beans are predominantly autogamous (self-fertilizing), unlike their close relative, the scarlet runner beans, Phaseolus coccineus L., which are allogamous (cross-fertilizing). Present-day domesticated bean populations from the Mesoamerican gene pool are highly differentiated (Zizumbo-Villarreal et al., 2005; Kwak \& Gepts, 2009).

Bruchid beetles (Coleoptera: Bruchidae) are among the most important pests of bean seeds in Mexico. Bruchids develop inside the bean from the first instar to the adult stage. Two Acanthoscelides species feed on both P. vulgaris and $P$. coccineus bean seeds in Mexico. Acanthoscelides obvelatus Bridwell is univoltine (Alvarez et al., 2005a) and mostly found on wild beans and at higher altitudes than its sibling species A. obtectus Say (Alvarez et al., 2005b). The multivoltine trait of A. obtectus and its ability to exploit the year-round fruiting of wild beans is likely to have favored its adaptation to granaries (Alvarez et al., 2005b). Two Zabrotes species, Z. subfasciatus Boheman and $Z$. sylverstris, also feed on P. vulgaris in Mexico (Romero \& Johnson, 1999), with Z. sylverstris being predominant between altitudes of $1200 \mathrm{~m}$ to $2000 \mathrm{~m}$ (Aebi et al., 2008).

Members of the genus Horismenus Walker (Hymenoptera: Chalcidoidea: Eulophidae: Entedoninae) are the most abundant parasitoids associated with wild and domesticated beans in Mexico (Hansson et al., 2004). This genus includes parasitoids and hyperparasitoids known to attack larvae of Lepidoptera, Coleoptera and Hymenoptera. Four Horismenus species (H. butcheri Hansson; Aebi \& Benrey, H. depressus Gahan; H. missouriensis Ashmead; and $H$. productus Ashmead) have been identified from beans infested by A. obvelatus, A. obtectus, Z. subfasciatus and Z. sylverstris in Mexico (Bonet, 2009). A fourth rare species is currently being described using both morphological and genetic characters (Hansson, Kenyon and Benrey, unpublished data).

Wolbachia endosymbionts are known to express different lifestyles, from mutualism to parasitism (Werren et al., 2008). They can affect the reproductive success of their host through male-killing (Hurst et al., 1999), male feminization (Rigaud et al., 1991), cytoplasmic incompatibility (Yen \& Barr, 1973) and induction of thelytokous parthenogenesis (Stouthamer \& Luck, 1993). Because endosymbiotic bacteria are transmitted maternally (much like mitochondria), the hitchhiking effect associated with Wolbachia tends to alter the frequency distribution of mtDNA haplotypes in infected host populations (e.g. Charlat et al., 2009; Yu et al., 2011). 


\section{Methods \\ Sampling}

With the goal of identifying historical and contemporary factors structuring the genetic diversity of Horismenus spp. at the population scale, three regions were targeted for sampling (A, B and C; fig. 1). Small fields of local bean varieties ( $P$. vulgaris and $P$. coccineus) were sampled to maximize the probability of finding beans infested with beetles since the use of pesticides is common in larger commercial fields.

Sixty sites were sampled during the dry season from January to March 2008, ranging from latitude $18^{\circ} 33^{\prime} 38.4^{\prime \prime}$ to $20^{\circ} 03^{\prime} 47.8^{\prime \prime} \mathrm{N}$ and from longitude $97^{\circ} 28^{\prime} 11.3^{\prime \prime}$ to $101^{\circ} 49^{\prime} 43.8^{\prime \prime} \mathrm{W}$, in the southern altiplano of Mexico characterized by high altitudes (see table S1). Farmers typically harvest their crops from August to February. Beans were either sampled in the field, collected from plants left behind following harvest or purchased directly from farmers or at local markets. GPS coordinates and altitude of each sampling site were either recorded in the field or deduced from information provided by farmers. One to two kilograms of dry beans per site were brought back to the laboratory, placed into 1-1 plastic containers with holes for ventilation, and stored at room temperature $\left(18-25^{\circ} \mathrm{C}\right)$. Emerged parasitoids and beetles were removed every two to three days and observations continued for 14 days after the last emergence. Parasitoids were individually preserved in vials with $100 \%$ ethanol for DNA extraction and beetles were identified to genus. Only samples from sites that produced six or more individuals from a single Horismenus species were retained for population level analyses.

Sixteen of the 60 sample sites had enough Horismenus specimens for analysis (table S1). Field collections from previous and ongoing studies (Benrey \& Kenyon, unpublished data), indicate that beans collected in the southern altiplano of Mexico are infested primarily by Acanthoscelides beetles (Alvarez et al., 2005a).

\section{Community structure}

Individuals from the Horismenus complex, the most abundant parasitoids emerging from beetle-infested beans, were identified using a taxonomic key based on morphological traits (Hansson et al., 2004). Prior to the population genetics analyses, we ensure that DNA sequences of COI clustered in monophyletic groups, validating the morphological identification of Horismenus species we previously made. Principal components analysis (PCA) was used to examine differences in Horismenus species abundances among sampling sites. Hellinger transformations (Legendre \& Gallagher, 2001) were first applied to the matrix of species abundance before PCA analysis using the $\mathrm{R}$ language 'Vegan' package (Oksanen et al., 2008).

\section{Genetic analyses}

Genomic DNA was extracted from the individual Horismenus abdomens using standard proteinase $\mathrm{K}$ digestion, phenol-chloroform extraction and precipitation with ethanol (Sambrook \& Russell, 2001). Extractions were screened for mitochondrial DNA variation using single strand conformation polymorphism (SSCP) (Orita et al., 1989; Sheffield et al., 1993), of a 278 bp segment of cytochrome c oxidase subunit I

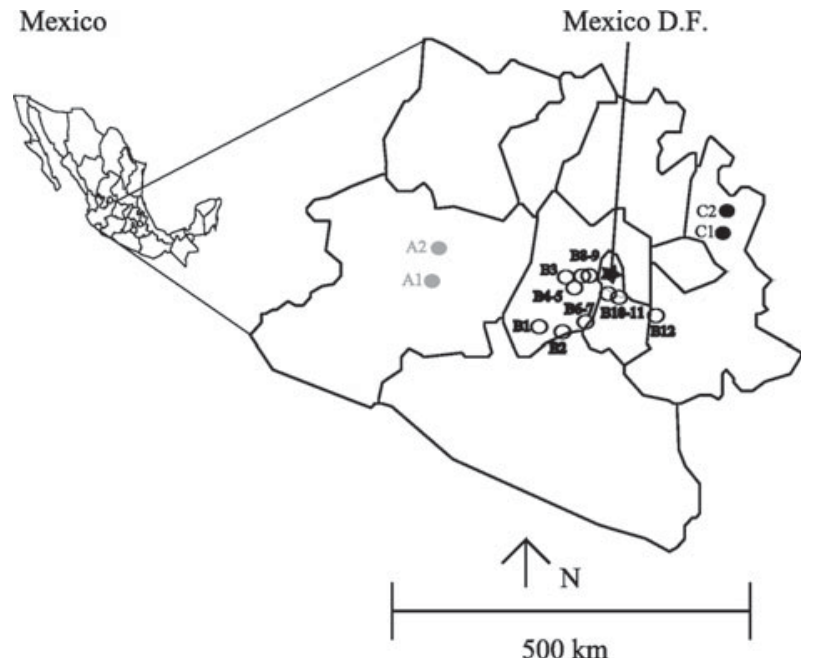

Fig. 1. Sampling sites in the southern altiplano of Mexico. Circles represent sites that were used in this study. Three regions are identified with letters $\mathrm{A}, \mathrm{B}$, and $\mathrm{C}$.

(COI). SSCP is known to be $99 \%$ accurate for differentiating sequence fragments between 100 and 300 bp (Smith \& Wayne, 1996). Primers 130F (5' CGGGGGTTAGITCIATTATAGG 3') and 430R (5' TTCATAGACTCATTACAAATTATATGAG 3'), were designed from sequences obtained from GenBank to amplify the COI segment nested in the standard 'COI barcoding' fragment and to avoid the amplification of Wolbachia endosymbionts. Amplification reactions were carried out in $12.5 \mu \mathrm{l}$ volumes, including $1.25 \mu \mathrm{l}$ of $10 \times$ reaction buffers (GenScript USA Inc., Piscataway, NJ, USA), $1.25 \mu \mathrm{l}$ of $10 \%$ trehalose (Fisher Scientific, Ottawa, Canada) solution, $1.5 \mathrm{mM} \mathrm{MgCl}_{2}$ (Genscript USA Inc.), $0.2 \mathrm{mM}$ of each dNTP (Genscript USA Inc.), $0.4 \mu \mathrm{M}$ of each primer, $0.5 \mathrm{U}$ of Taq DNA polymerase (Genscript USA Inc.) and $2 \mu \mathrm{l}$ of DNA template. Conditions used with a Bio-Rad thermocycler were as follows: $92^{\circ} \mathrm{C}$ for $30 \mathrm{~s}, 35$ cycles of $48^{\circ} \mathrm{C}$ for $15 \mathrm{~s}, 68^{\circ} \mathrm{C}$ for $30 \mathrm{~s}$ and one final cycle of $68^{\circ} \mathrm{C}$ for $1 \mathrm{~min}$. Amplified products were electrophoresed on a nondenaturing polyacrylamide gel (6\%) (Angers \& Bernatchez, 1998) and visualized using silver nitrate staining (Bassam et al., 1991). Conformers were first scored within a population on a gel and then different conformers from different populations were compared on a new gel.

\section{DNA sequencing}

Each different conformer detected on SSCP was reamplified for sequencing in $50 \mu \mathrm{l}$ volumes, and PCR products were purified using the QIAquick purification kit (Qiagen Inc., Mississauga, Canada). PCR sequencing was performed with the Big Dye terminator cycle sequencing kit version 1.1 (Applied Biosystems, Inc., Foster City, CA, USA). Sequencing was performed with an Applied Biosystem ABI 3730 DNA analyzer. Chromatograms of all sequences were checked with FinchTV 1.4.0 (Geospiza Inc., Seattle, WA, USA). Sequences were then checked with BioEdit (Hall, 1999) and aligned using Clustal X version 1.83 (Thompson et al., 1997). Nucleotide sequence data were deposited in GenBank database under the accession numbers (JX068543-JX068599). 


\section{Screening of Wolbachia endosymbionts}

The presence of Wolbachia bacteria in samples was detected using a PCR assay. A maximum of 30 individuals was tested for each population. Specific primers, $\mathrm{wbcF} \quad\left(5^{\prime}\right.$ GCACTTCATGTTGCTGGTATGTCATCAATT 3') and wbcR (5' CTTGGATGACCAAAAAATCAAAACAGGTG 3'), were designed to amplify a $280 \mathrm{bp}$ fragment of COI. We ensured specificity of primers by designing them from conserved regions of aligned Wolbachia COI sequences taken from GenBank (Drosophila melanogaster; Decevania sp.; Culex quinquefasciatus: (AE017196.1; AY800177.1; AM999887.1)) and the one obtained in this study (GenBank: JX068600) with the 2154bee and 2492-bee primers (Simon et al., 1994). This guarantees that the primers are not specific to a Wolbachia strain. The same conditions as described above were used for the amplification, with the exception of an adjusted annealing temperature of $51^{\circ}$ C. Wolbachia occurrence was inferred from the amplification product as revealed by electrophoresis on a $1.5 \%$ agarose gel.

\section{Genetic analyses}

\section{Phylogenetic relationships and molecular identification}

Phylogenetic analyses were used to test morphological parasitoid identification by ensuring that different taxa fall into the appropriate clade. Phylogenetic relationships among Horismenus species were inferred using Bayesian (BI) and maximum likelihood (ML) methods as implemented in the Phylobayes 3 (Lartillot et al., 2009) and Phylml (Guindon \& Gascuel, 2003) programs, respectively. The best-fit substitution model $(\mathrm{GTR}+\Gamma)$ was determined using MODELTEST 3.7 (Posada \& Crandall, 1998). Sequences from Entedon sp. (GenBank: DQ149194), Torymus benefices (GenBank: AB070504.1) and Megastigmus transvaalensis (GenBank: AF420405) were used as outgroups. Each BI analysis was initiated with a random starting tree, included two parallel Markov chain Monte Carlo runs and with 400,000 iterations sampled every 1000 iterations, until convergence (maximum discrepancy across all bipartions <0.1). A $50 \%$ majority rule consensus tree was constructed from the remaining trees after discarding the first 40,000 iterations (burn-in) of sampled trees. ML analysis was conducted with five ML tree searches with 100 bootstrapping replicates. The ML tree with the highest likelihood value was used to plot bootstrap values.

\section{Genetic diversity, structure and differentiation}

We first characterized the molecular diversity of parasitoid populations to investigate population genetic structure and differentiation under different geographic models or Wolbachia infection status. Measures of population genetic diversity, including the number of haplotypes $(n)$, the number of sequenced haplotypes (s), haplotype diversity (hd) (Nei \& Tajima, 1981), nucleotide diversity $(\pi)$ (Nei, 1987) and the number of substitutions ( $n \mathrm{~s})$ were estimated from mitochondrial DNA polymorphism using the computer program Arlequin 3.0 (Excoffier et al., 2005). A matrix of mutational differences among haplotypes was calculated to produce a minimum length spanning network of haplotypes using the same software. Nodes of the network represent the haplotypes, while branch length is proportional to the number of mutations between them.
Genetic diversity found within versus among populations was estimated by computing global and pairwise $F_{\mathrm{ST}}$ (Weir \& Cockerham, 1984) using Arlequin 3.0 (Excoffier et al., 2005). This was also quantified by using global and pairwise $\Phi_{\mathrm{ST}}$ (Excoffier et al., 2005) to take into account the mutational differences among haplotypes. In order to determine if the mutations contributed significantly to genetic differentiation, the difference between global $F_{\mathrm{ST}}$ and $\Phi_{\mathrm{ST}}$ values was tested using a randomization procedure implemented in SPAGeDi 1.1 (Hardy \& Vekemans, 2002). Hierarchical analyses of the genetic diversity (Excoffier et al., 1992) were also performed using Arlequin 3.0 (Excoffier et al., 2005). A priori criteria for grouping were tested according to the three different geographical regions sampled (A, B and C; fig. 1). Grouping by Wolbachia infection status was used to test differentiation by estimating global $F_{\mathrm{ST}}$ among infected vs. non-infected individual.

Spatial structure was also investigated by autocorrelation analysis based on the Moran's II coefficient calculated using the AIDA software (Bertorelle \& Barbujani, 1995). For $H$. depressus and H. missouriensis, the Moran's II coefficient was calculated for four and three distance classes (table S2), respectively, as implemented in AIDA software (Bertorelle \& Barbujani, 1995). The shape of the correlogram (Moran's II coefficient plotted against geographic distance) represents the pattern of genetic similarity over space.

\section{Results}

\section{Community structure}

Horismenus depressus and $H$. missouriensis were the most abundant species parasitizing beetles on seeds of $P$. vulgaris, while $H$. butcheri and $H$. sp. were the predominant species on P. coccineus (table 1). Horismenus species represent $87 \%$ of all emerging parasitoids. The two most abundant Horismenus species tended to segregate among sample sites, clustering, respectively, in the first and second quadrant of the PCA projection (fig. S1), except for three sites (B3, B10 and A2) where the two species were collected together.

\section{Genetic diversity}

\section{Within species diversity}

We were unable to amplify any DNA fragment from 17 individuals. The 600 remaining extractions revealed, by SSCP screening, 80 distinct COI haplotypes for over the four Horismenus species. Fifty-eight haplotypes were detected in $H$. depressus $(N=332)$, nine in $H$. missouriensis $(N=194), 11$ in $H$. butcheri $(N=59)$ and two in Horismenus sp. $(N=15)$. Fiftyseven of these were sequenced: $42 / 58$ for $H$. depressus, $7 / 9$ for $H$. missouriensis, 6/11 for $H$. butcheri and $2 / 2$ for $H$. sp (table 2). These sequences clustered into four monophyletic clades where $H$. depressus, $H$. missouriensis and $H$. butcheri were wellsupported by BI and ML analyses (fig. 2). The H. sp. clade was poorly supported. Each cluster was found to correspond to a given morphological species. Intraspecific divergence was high for $H$. depressus $(6.5 \%), H$. butcheri $(6.0 \%)$ and $H$. sp. (3.2\%), but low for H. missouriensis $(0.4 \%)$.

\section{Population diversity}

The SSCP survey identified between two and 12 haplotypes per population of $H$. depressus. For $H$. missouriensis, one 
Table 1. Abundances of parasitoids, bruchid beetles (Acanthoscelides and Zabrotes), and the bean species from which studied insects emerged.

\begin{tabular}{|c|c|c|c|c|c|c|c|c|c|c|c|c|c|c|c|c|c|}
\hline \multirow[t]{2}{*}{ Trophic level } & \multirow[t]{2}{*}{ Species } & \multicolumn{2}{|c|}{ West (A) } & \multicolumn{12}{|c|}{ Central (B) } & \multicolumn{2}{|c|}{ East (C) } \\
\hline & & $\mathrm{A} 1$ & $\mathrm{~A} 2$ & $\mathrm{~B} 1$ & B2 & B3 & B4 & B5 & B6 & B7 & B8 & B9 & $\mathrm{B} 10$ & B11 & B12 & $\mathrm{C} 1$ & $\mathrm{C} 2$ \\
\hline 3 & H. depressus & 16 & 17 & 27 & 124 & 3 & - & 0 & 0 & 36 & 14 & 21 & 31 & 18 & - & 34 & 4 \\
\hline 3 & H. missouriensis & - & 106 & 2 & 1 & 6 & 9 & 24 & 30 & 5 & 1 & - & 24 & - & - & - & - \\
\hline 3 & H. butcheri & - & - & - & 22 & - & - & - & - & - & 2 & - & 2 & - & - & - & 39 \\
\hline 3 & H. sp & - & - & - & - & - & - & - & - & - & - & - & 4 & - & 11 & - & - \\
\hline$?$ & Others parasitoids & 1 & - & - & 36 & - & 1 & - & - & 31 & - & 5 & 1 & 21 & - & - & - \\
\hline 2 & Ancanthocelides & 856 & 989 & 148 & 2331 & 209 & 119 & 459 & 553 & 2410 & 203 & 1295 & 587 & 186 & 32 & 815 & 2850 \\
\hline 2 & Zabrotes & 26 & - & 37 & 3 & 1 & - & - & 10 & 374 & - & - & - & - & - & - & - \\
\hline 1 & Beans species & $\mathrm{v}$ & $\mathrm{v}$ & $\mathrm{v}$ & $\mathrm{v}$ & $\mathrm{v}$ & $\mathrm{v}$ & $\mathrm{v}$ & $\mathrm{v}$ & $\mathrm{v}$ & $\mathrm{v}$ & $\mathrm{v}$ & $\mathrm{v}$ & $\mathrm{v}$ & $\mathrm{c}$ & $\mathrm{v}$ & $\mathrm{v} \& \mathrm{c}$ \\
\hline
\end{tabular}

v: Phaseolus vulgaris; c: Phaseolus coccineus.

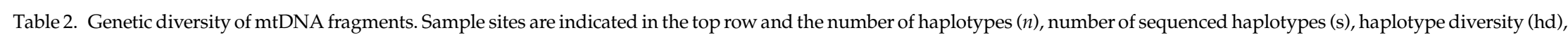
nucleotide diversity $(\pi)$, and number of substitutions (ns) are indicated for each species.

\begin{tabular}{|c|c|c|c|c|c|c|c|c|c|c|c|c|c|c|c|c|c|c|c|}
\hline & $\mathrm{A} 1$ & A2 & B1 & B2 & B3 & B4 & B5 & B6 & B7 & B8 & B9 & B10 & B11 & B12 & $\mathrm{C} 1$ & $\mathrm{C} 2$ & Total & Means & $\mathrm{SD}$ \\
\hline \multicolumn{20}{|c|}{ H. depressus } \\
\hline$n$ & 2 & 3 & 9 & 12 & & & & & 9 & 5 & 3 & 4 & 3 & & 8 & & 58 & 5.8 & 3.4 \\
\hline $\mathrm{s}$ & 2 & 1 & 7 & 9 & & & & & 6 & 3 & 3 & 4 & 3 & & 4 & & 42 & 4.2 & 2.4 \\
\hline hd & 0.40 & 0.49 & 0.88 & 0.83 & & & & & 0.78 & 0.54 & 0.49 & 0.31 & 0.41 & & 0.62 & & - & 0.6 & 0.2 \\
\hline$\pi$ & 0.92 & 0.00 & 5.07 & 6.55 & & & & & 5.05 & 2.07 & 1.61 & 3.34 & 0.66 & & 4.55 & & - & 3.0 & 2.2 \\
\hline$n s$ & 2 & 0 & 19 & 22 & & & & & 16 & 9 & 6 & 20 & 3 & & 20 & & 42 & 11.6 & 8.4 \\
\hline \multicolumn{20}{|c|}{ H. missouriensis } \\
\hline$n$ & & 3 & & & 2 & 1 & 1 & 3 & & & & 4 & & & & & 9 & 2.3 & 1.2 \\
\hline s & & 1 & & & 1 & 1 & 1 & 1 & & & & 2 & & & & & 7 & 1.2 & 0.4 \\
\hline hd & & 0.11 & & & 0.33 & 0.0 & 0.0 & 0.20 & & & & 0.61 & & & & & - & 0.2 & 0.2 \\
\hline$\pi$ & & 0.00 & & & 0.00 & 0.0 & 0.0 & 0.00 & & & & 0.13 & & & & & - & 0.0 & 0.1 \\
\hline$n \mathrm{~s}$ & & 0 & & & 0 & 0 & 0 & 0 & & & & 1 & & & & & 1 & 0.2 & 0.4 \\
\hline \multicolumn{20}{|c|}{ H. butcheri } \\
\hline$n$ & & & & 1 & & & & & & 2 & & 1 & & & & 7 & 11 & 2.8 & 2.9 \\
\hline $\mathrm{s}$ & & & & 0 & & & & & & 2 & & 1 & & & & 3 & 6 & 1.5 & 1.3 \\
\hline hd & & & & 0.00 & & & & & & 1.00 & & 0.00 & & & & 0.64 & - & 0.4 & 0.5 \\
\hline$\pi$ & & & & 0.00 & & & & & & 1.00 & & 0.00 & & & & 0.28 & - & 0.3 & 0.5 \\
\hline$n \mathrm{~s}$ & & & & - & & & & & & 2 & & 0 & & & & 8 & 23 & 2.5 & 3.8 \\
\hline
\end{tabular}




\section{PP GTR $+\Gamma /$ BS GTR $+\Gamma$}

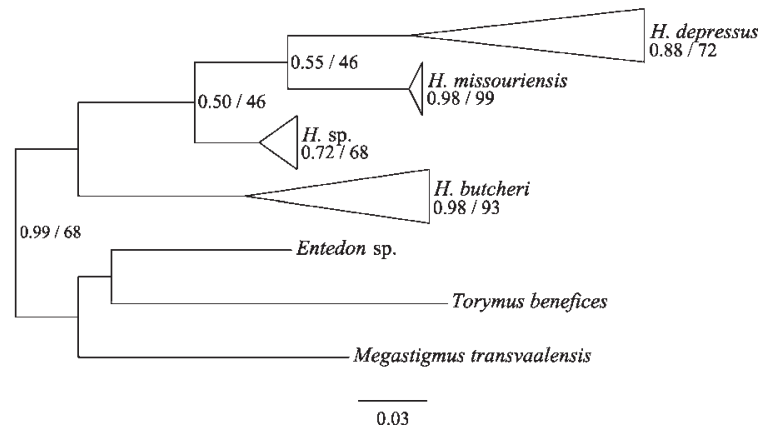

Fig. 2. Monophyletic group differentiation by Bayesian and maximum likelihood analysis of the observed COI sequences of the SSCP survey. Bayesian posterior probabilities (PP) and ML bootstrap support values (BS) are shown in this order for each clade on the tree obtained by BI analysis.

to four haplotypes were found, with two populations (B4 and B5) having a unique fixed haplotype. For $H$. butcheri, one to seven haplotypes were identified, with one population (B2) having a fixed unique haplotype. The two $H$. sp. populations (B10 and B12) each had distinct fixed haplotypes.

Haplotype networks revealed contrasting patterns between $H$. depressus and $H$. missouriensis (fig. 3A-B). Horismenus depressus displayed a large number of private haplotypes (detected in a single population), with only haplotype h03 detected in more than one population. In addition, the nucleotide diversity was generally very high within most populations ( $\pi=3.0$; table 2 ) due to the coexistence of highly divergent haplotypes. For instance, haplotypes h05 and $\mathrm{h} 06$ detected in the $\mathrm{C} 1$ population differed by ten mutations (fig. 3A). In contrast, one unique haplotype was detected in five of six $H$. missouriensis populations, and the additional haplotype differed by only a single mutation (fig. 3B). As a result, nucleotide diversity was very low for populations of $H$. missouriensis.

\section{Genetic structure}

The estimated values of $F_{\mathrm{ST}}$ and $\Phi_{\mathrm{ST}}$ for $H$. depressus were 0.3872 and 0.4376 , respectively $\left(P=0.0349 ; N_{\mathrm{ST}}=0.6069\right)$. Both estimators were calculated using only the 42 haplotypes for which sequencing was performed, corresponding to $87 \%$ of sampled individuals. However, the difference between $F_{\mathrm{ST}}$ and $\Phi_{\mathrm{ST}}$, is driven by only two populations (B10 and B11) that are characterized by very low diversity. When these sites are removed from the analyses, $F_{\mathrm{ST}}(0.3403)$ and $\Phi_{\mathrm{ST}}(0.3191)$ become similar and statistically not different $(P=0.9674)$, which assess the absence of molecular information.

Geographical grouping by region A, B, and C (fig. 1), does not result in a significant $F_{\mathrm{CT}}$ estimate (table 3 ) for $H$. depressus. Another way to test the genetic structure is by computing Moran's II autocorrelation coefficient values for different distance classes. For $H$. depressus, all Moran's II coefficients were significant $(P<0.005)$ and ranged from low positive values transitioning to increasingly negative values with added distance (fig. S2). Except for the first distance class (within populations) where low autocorrelation was detected, the set of coefficients shown in the correlogram can be attributed to the random spatial distribution of haplotypes since they are close to zero. For H. missouriensis, no significant Moran's II values were detected. This also indicates the absence of spatial patterns of DNA diversity (Bertorelle \& Barbujani, 1995).

The estimations of $F_{\mathrm{ST}}(0.9317)$ and $\Phi_{\mathrm{ST}}$ (0.9317) for $H$. missouriensis were higher than for $H$. depressus. However, most of the inter-population diversity is driven by a single population (B4), which was not infected by Wolbachia and was fixed for a distinct haplotype. Removing this population decreased $F_{\mathrm{ST}}$ to 0.0604 and $\Phi_{\mathrm{ST}}$ to 0.0604 , reflecting an insignificant level of population differentiation.

\section{Wolbachia}

Screening for the presence of Wolbachia revealed that most of the $H$. missouriensis populations were infected (5/6; table 1). The bacteria were not detected in the other Horismenus species. Up to $83 \%$ of tested individuals within a population were infected by Wolbachia (table 4). Infection status was restricted to only one mtDNA haplotype (A2:B3:B5:B6:B10.h59; fig. 3B). Grouping individuals from $H$. missiouriensis populations by Wolbachia infection status leads to a significant differentiation $\left(F_{\mathrm{ST}}=0.10914 ;\right.$ table 3$)$.

\section{Discussion}

The aim of this study was to compare the evolutionary history of parasitoids to those of their bruchid beetle hosts and their domesticated host plant in Mexico. Consistent structure among members of different trophic levels is expected in the presence of strong ecological interactions. Consequently, we predicted that the genetic structure of host and parasitoid populations would be congruent because they have been similarly influenced by human-mediated migration since the beginning of the domestication process. On the other hand, parasitoid structure could be biased by the presence of Wolbachia endosymbionts.

We found four Horismenus species that emerged from Acanthoscelides spp. that had infested domesticated beans, while a previous study found only one species, $H$. missouriensis (Aebi et al., 2008). The two most abundant species, H. depressus and $H$. missouriensis, tended to segregate among sampled sites and emerged predominantly from infested $P$. vulgaris seeds. Although uncommon, $H$. butcheri and $H$. sp. were the most abundant species on $P$. coccineus seeds. However, populations of these two species were too few to be meaningfully analyzed.

\section{A blurred evolutionary history}

Populations of $H$. depressus and $H$. missouriensis exhibited different patterns of mitochondrial diversity. Horismenus missouriensis showed very low within-species diversity, with one haplotype shared by nearly all populations. This low diversity appears to be linked to the presence of Wolbachia, which was detected exclusively in this species. Both Wolbachia and mtDNA are transmitted maternally, and the reproductive manipulation by the bacteria (e.g. cytoplasmic incompatibility) tends to alter the frequency distribution of mtDNA haplotypes within host populations (Charlat et al., 2009; Yu et al., 2011). This also may explain the marked difference between infected and uninfected individuals of $H$. missouriensis (table 4), and this would be the first report that we are aware of suggesting that Wolbachia infection lowers mtDNA 

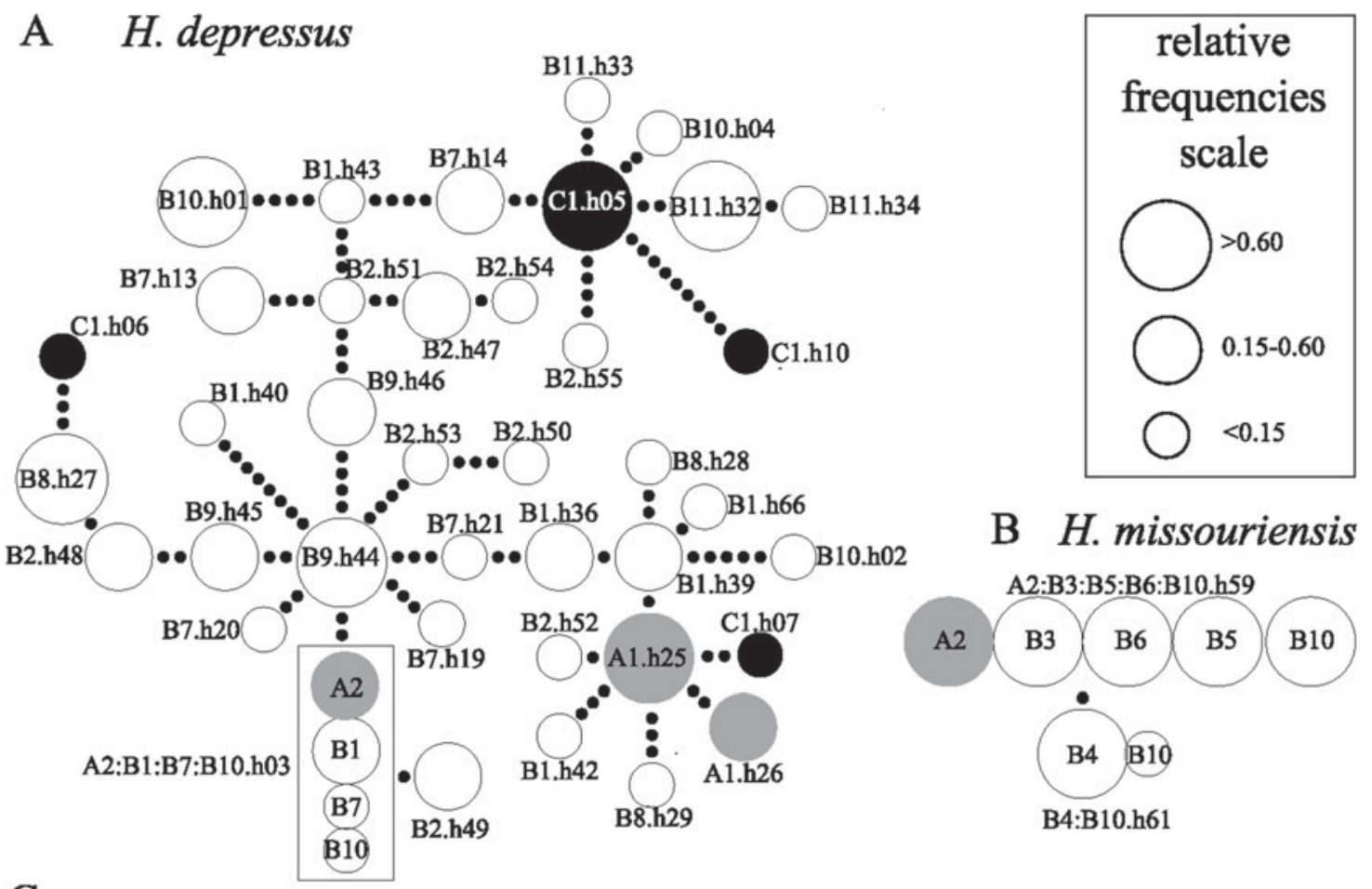

\section{B H. missouriensis}

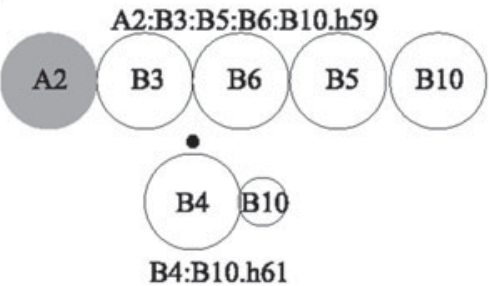

$\mathrm{C}$
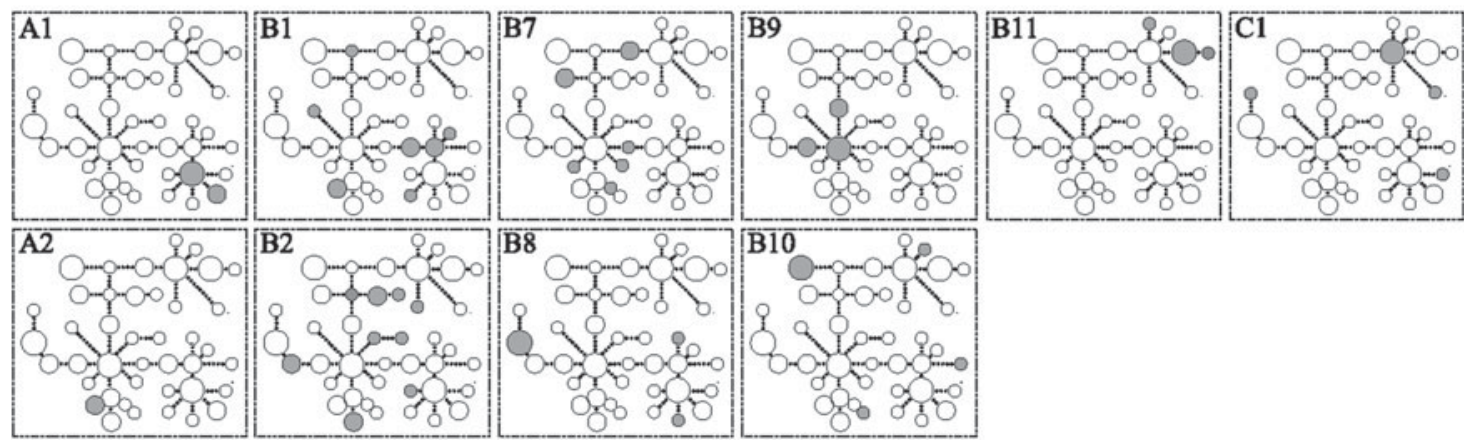

Fig. 3. Minimum spanning network of mtDNA haplotypes for the (A) ten populations of $H$. depressus (291 individuals) and (B) six populations of $H$. missouriensis ( 175 individuals). Colors correspond to the three sampling regions: grey for $\mathrm{A}$, white for $\mathrm{B}$ and black for $\mathrm{C}$ (fig. 1). For each circle representing an observed haplotype, there is a sample site and haplotype identifier. The size of each circle is scaled to its relative haplotype frequency according to the SSCP survey. Small black circles indicate unsampled intermediate haplotypes. The haplotype (A2:B1:B7:B10.h03) contained in a box have been detected in four populations. (C) Representation of the distribution of the 42 haplotypes among the ten $H$. depressus populations studied within the minimum spanning network.

diversity of parasitoid populations. The genetic diversity of spider mite (Tetranychus urticae) populations was also reported to be lowered by Wolbachia infection in China (Yu et al., 2011). Another explanation for the low genetic diversity of H. missouriensis and its infection by Wolbachia would be that a bottleneck before the dispersal of this haplotype coincided with the presence of Wolbachia by chance.

Therefore, it is not possible to determine on the basis of the mitochondrial data, whether $H$. missouriensis has evolved in parallel with other Horismenus species, since its historical signal has likely been blurred by the effects of Wolbachia infection. Interestingly, the broad geographic range of a single infected haplotype may indicate at least one relatively recent historical dispersal event (table 5). Future studies should include more data on the genetic diversity of Wolbachia that could enhance the understanding of the evolutionary history of its hosts (Lozier et al., 2007).

\section{Inconsistent genetic structure among trophic levels}

Populations of $H$. depressus, were found to be strongly differentiated even over short geographic distances. Unlike $H$. missouriensis, high levels of sequence divergence were detected within $H$. depressus. However, relatively low $F_{\mathrm{ST}}$ and $\Phi_{\mathrm{ST}}$ estimates were observed due to the very high intrapopulation diversity, with a large number of distinct haplotypes and abundant mutations among haplotypes. The polyphyly characterizing lineages within $H$. depressus 
Table 3. Hierarchical analyses of the genetic diversity of $H$. depressus and $H$. missouriensis populations. Groups were defined by geographic region (A, B, and C; fig. 1) for $\mathrm{H}$. depressus without the B10 and B11 sites (see Results: Population diversity section). Two groups were defined by infection statue of $H$. missouriensis by Wolbachia.

\begin{tabular}{|c|c|c|c|c|c|c|c|c|c|}
\hline Dataset & Group & $n^{*}$ & $\begin{array}{l}\text { Source of } \\
\text { variation }\end{array}$ & $\mathrm{df}$ & $\begin{array}{l}\text { Sum of } \\
\text { squares }\end{array}$ & $\begin{array}{c}\text { Variance } \\
\text { components }\end{array}$ & $\begin{array}{c}\text { Percentage of } \\
\text { variation }\end{array}$ & $\begin{array}{c}\text { Fixation } \\
\text { indices }\end{array}$ & $P$-value \\
\hline \multirow{3}{*}{ H. depressus $ф$} & West & 33 & Among groups & 2 & 11.787 & 0.02288 & 4.38 & $F_{\mathrm{CT}}=0.04381$ & $P=0.12877$ \\
\hline & East & 33 & Within populations & 278 & 100.835 & 0.36271 & 69.45 & $1-F_{\mathrm{ST}}=0.69448$ & \\
\hline & & 286 & Total & 285 & 135.594 & 0.52228 & & $F_{\mathrm{ST}}=0.30552$ & $P<0.00000$ \\
\hline \multirow[t]{2}{*}{ H. missouriensis } & Infected & 33 & Among populations & 1 & 1.185 & 0.02105 & 10.91 & & \\
\hline & & 122 & Total & 121 & 21.803 & 0.19287 & & $F_{\mathrm{ST}}=0.10914$ & $P=0.00079$ \\
\hline
\end{tabular}

$\Varangle$ Group 1: A1, A2; Group 2: B1, B2, B7, B8, B9; Group 3: C1.

Table 4. Number of H. missouriensis individuals infected with Wolbachia.

\begin{tabular}{lc}
\hline Sample sites & Number of individuals infected/tested (\%) \\
\hline A2 & $6 / 30(20 \%)$ \\
B3 & $5 / 6(83 \%)$ \\
B4 & $0 / 9(0 \%)$ \\
B5 & $8 / 24(33 \%)$ \\
B6 & $9 / 30(30 \%)$ \\
B10 & $5 / 24(21 \%)$ \\
\hline
\end{tabular}

populations (fig. 3C) suggest that the actual population structure is recent (i.e. Karlin \& Nevo, 1986). The analyses also suggest that the absence of historical structure in the system results from the random dispersal of haplotypes among regions and populations as illustrated in fig. $3 \mathrm{C}$. The level of genetic differentiation found for $H$. depressus is similar to that reported for one of its bruchid hosts, Zabrotes subfasciatus (Shani \& Benrey, unpublished data; GonzalezRodriguez et al., 2002: see table 5). However, human-mediated migration cannot be considered as a relevant contemporary factor for $H$. depressus parasitoids, as it has been assumed to be the case for its two Acanthoscelides beetle hosts (Alvarez et al., 2007; Restoux et al., 2010: table 5). The two Acanthoscelides species, the most abundant bruchids, have low levels of differentiation even over long distances (Alvarez et al., 2007; Restoux et al., 2010). Negligible genetic differentiation among Acanthoscelides populations suggests at least one recent historical dispersal event, which was presumed to be a consequence of human seed trade (Alvarez et al., 2007; Restoux et al., 2010). It also suggests that there has been insufficient time since dispersal to allow for differentiation among populations. Interestingly, Z. subfasciatus populations were found to be well differentiated and organized by dispersal (Shani \& Benrey, unpublished data; GonzalezRodriguez et al., 2002). The spatial genetic structure of $H$. depressus is also similar to that of its host plant, consisting of random historical dispersal from a highly diversified ancestral gene pool (Papa \& Gepts, 2003; Zizumbo-Villarreal et al., 2005; Kwak \& Gepts, 2009; Rossi et al., 2009).

Present-day domesticated bean populations from the Mesoamerican gene pool are highly differentiated and are now structured by dispersal, while their wild relatives are structured by vicariance (Papa \& Gepts, 2003;
Zizumbo-Villarreal et al., 2005; Kwak \& Gepts, 2009; Rossi et al., 2009). Human-mediated seed dispersal, in addition to genetic drift, selection by growers and environmental pressures, have affected the genetic diversity of insects since the beginning of domestication (Papa \& Gepts, 2003; ZizumboVillarreal et al., 2005; Blair et al., 2009; Kwak \& Gepts, 2009; Rossi et al., 2009).

\section{Evolutionary dynamics}

Inconsistent patterns among trophic levels could be explained by distinct evolutionary dynamics. In spite of an extensive human-mediated migration that homogenized the population structure of beetle hosts, parasitoid populations (H. depressus) remain highly differentiated, and therefore parasitoids likely migrate from wild-weedy bean populations adjacent to crop fields.

The relatively high nucleotide and haplotype diversity within $H$. depressus populations indicates the existence of a large and stable population with a long evolutionary history and subsequent contacts among differentiated lineages associated with wild beans. This corresponds with the fourth category, defined by Grant \& Bowen (1998), to infer on the likelihood of mtDNA lineages survival under peculiar demographic scenarios. The maintenance of ancestral lineages in the Horismenus parasitoid complex suggests past fragmentation and restricted gene flow among parasitoid populations. The complex topography of the southern altiplano of Mexico (i.e. a large range of altitudes), together with the limited effect of the last glaciations (i.e. altitudinal effect: Bryant \& Holloway, 1985; Ramamoorthy, 1998), may constitute important factors favoring the conservation of mtDNA lineages in subdivided populations. Furthermore, subdivided populations have the capacity to retain more diversity as drift may operate distinctly within each subpopulation. However, genetic drift within extinction-recolonization dynamics could be responsible for the absence of a large number of intermediate haplotypes with respect to limited sampling effort.

Parasitoids may not have a large enough capacity for dispersal between crop fields and houses where seeds are stored. Furthermore, they may not be able to survive storage conditions since they need other sources of nutrition (e.g. nectar and pollen). On the other hand, the bruchid beetle hosts are well pre-adapted to storage conditions since they consume dry seeds and show polymorphism in dispersal and 
Table 5. Comparison within and among trophic levels, information on the third trophic level were obtained in this study and information on the first and second trophic levels came from previously published studies.

\begin{tabular}{|c|c|c|c|c|c|c|c|c|}
\hline $\begin{array}{l}\text { Trophic } \\
\text { level }\end{array}$ & Species & $\begin{array}{l}\text { Region } \\
\text { of study }\end{array}$ & $\begin{array}{l}\text { Number of } \\
\text { individuals }\end{array}$ & Markers & $\begin{array}{c}\text { Differentiation } \\
\quad\left(F_{\mathrm{ST}}\right)\end{array}$ & $\begin{array}{l}\text { Inferred } \\
\text { patterns }\end{array}$ & $\begin{array}{c}\text { Putative } \\
\text { mechanisms }\end{array}$ & References \\
\hline 3 & H.depressus & SAM & 286 & mtDNA & 0.3403 & dispersal & HMM & This study \\
\hline 2 & A. obvelatus & SAM & 135 & microsatellites & 0.107 & dispersal & HMM & $\begin{array}{l}\text { (Alvarez et al., } \\
\text { 2007) }\end{array}$ \\
\hline 2 & Z. subfasciatus & SAM & 150 & allozymes & 0.305 & dispersal & HMM & $\begin{array}{l}\text { (Gonzalez- } \\
\text { Rodriguez } \\
\text { et al., 2002) }\end{array}$ \\
\hline 1 & P. vulgaris & Mexico & 134 & AFLP & $0.2275-0.4150$ & dispersal & HMM \& E\&GS & $\begin{array}{l}\text { (Papa \& Gepts, } \\
\text { 2003) }\end{array}$ \\
\hline
\end{tabular}

SAM: southern altiplano of Mexico.

HMM: human-mediated migration.

RMS: reproductive manipulation strategies.

E\&GS: environmental and grower selection.

reproductive traits (Tuda et al., 2006). Furthermore, A. obtectus has been found to exhibit resistance to several types of pesticides (Alvarez et al., 2005b). This species is now cosmopolitan while Horismenus parasitoids have a much more restricted distribution.

The surrounding environment could be responsible for the population genetic structure observed in Horismenus parasitoids since $H$. depressus populations are, even over short distances, highly differentiated (table 5). Traditional crop fields in Mexico are commonly surrounded by wild-weedy bean populations (Papa \& Gepts, 2003; Zizumbo-Villarreal et al., 2005) known to support far higher numbers of Horismenus parasitoids compared to domesticated bean populations (Laurin-Lemay, personal observations). In addition, local adaptation to highly differentiated wildweedy-domesticated bean complexes (Campan et al., 2005; Zizumbo-Villarreal et al., 2005) might also prevent gene flow.

Our data revealed inconsistent genetic structure among members of different trophic levels, as well as within a trophic level. Future research should focus on two main questions aimed to elucidate the microevolutionary processes occurring in this multitrophic system. First, what is the role of parasitoid populations associated with wild-weedy beans in structuring the genetic diversity of parasitoids attacking bruchids in crop fields? Second, what is the origin of migrants detected among all members of the system? Additional molecular data should then be obtained for a higher-resolution assessment of the phylogeographical inferences and the putative role of bean domestication on insect population structure.

\section{Acknowledgements}

This work was financially supported by the Canada Research Chair Program and the Swiss National Science Foundation (Project No. 31003A_127364). We thank Omar Arellano-Aguilar for help with sampling in Mexico and the Instituto de Ecologia at UNAM for logistical assistance. We thank Josée Doyon for technical assistance and Sarah Kenyon for comments on an earlier version of this paper and for help during field work in Mexico. We also thank the editor and two anonymous reviewers who provided thoughtful comments.

\section{Supplementary material}

The online figures and tables can be viewed at http:// journals.cambridge.org/ber.

\section{References}

Aebi, A., Shani, T., Hansson, C., Contreras-Garduno, J., Mansion, G. \& Benrey, B. (2008) The potential of native parasitoids for the control of Mexican bean beetles: A genetic and ecological approach. Biological Control 47, 289-297.

Alvarez, N., Hossaert-Mckey, M., Rasplus, J.Y., Mckey, D., Mercier, L., Soldati, L., Aebi, A., Shani, T. \& Benrey, B. (2005a) Sibling species of bean bruchids: a morphological and phylogenetic study of Acanthoscelides obtectus Say and Acanthoscelides obvelatus Bridwell. Journal of Zoological Systematics and Evolutionary Research 43, 29-37.

Alvarez, N., Mckey, D., Hossaert-Mckey, M., Born, C., Mercier, L. \& Benrey, B. (2005b) Ancient and recent evolutionary history of the bruchid beetle, Acanthoscelides obtectus Say, a cosmopolitan pest of beans. Molecular Ecology 14, 1015-1024.

Alvarez, N., Hossaert-Mckey, M., Restoux, G., DelgadoSalinas, A. \& Benrey, B. (2007) Anthropogenic effects on population genetics of phytophagous insects associated with domesticated plants. Evolution 61, 2986-2996.

Angers, B. \& Bernatchez, L. (1998) Combined use of SMM and non-SMM methods to infer fine structure and evolutionary history of closely related brook charr (Salvelinus fontinalis, Salmonidea) populations from microsatellites. Molecular Biology and Evolution 15, 143-159.

Bassam, B.J., Caetano-Anollés, G. \& Gresshoff, P.M. (1991) Fast and sensitive silver staining of DNA in polyacrylamide gels. Analytical Biochemistry 196, 80-83.

Bertorelle, G. \& Barbujani, G. (1995) Analysis of DNA diversity by spatial autocorrelation. Genetics 140, 811-819. 
Blair, M., Díaz, L., Buendía, H. \& Duque, M. (2009) Genetic diversity, seed size associations and population structure of a core collection of common beans (Phaseolus vulgaris L.). Theoretical and Applied Genetics 119, 955-972.

Bonet, A. (2009) New hosts, host plants, and distribution records for horismenus (Hymenoptera: Eulophidae) species in a bruchid beetle parasitoid guild attacking wild type Phaseolus coccineus and $P$. Vulgaris in Central Mexico. Florida Entomologist 91, 698-701.

Broughton, W.J., Hernández, G., Blair, M., Beebe, S., Gepts, P. \& Vanderleyden, J. (2003) Beans (Phaseolus spp.) - model food legumes. Plant and Soil 252, 55-128.

Bryant, V.M. \& Holloway, R.G. (1985) Pollen Records of LateQuaternary North American Sediments. Dallas, TX, USA, American Association of Stratigraphic Palynologists Foundation.

Campan, E.D.M., Callejas, A., Rahier, M. \& Benrey, B. (2005) Interpopulation variation in a larval parasitoid of bruchids, Stenocorse bruchivora (Hymenoptera: Braconidae): Host plant effects. Environmental Entomology 34, 457-465.

Charlat, S., Duplouy, A., Hornett, E.A., Dyson, E.A., Davies, N., Roderick, G.K., Wedell, N. \& Hurst, G.D.D. (2009) The joint evolutionary histories of Wolbachia and mitochondria in Hypolimnas bolina. Bmc Evolutionary Biology 9, 64.

Colwell, R.R., Simidu, U. \& Ohwada, K. (1996) Microbial Diversity in Time and Space. New York, USA, Plenum Press.

Doebley, J.F., Gaut, B.S. \& Smith, B.D. (2006) The molecular genetics of crop domestication. Cell 127, 1309-1321.

Excoffier, L., Smouse, P.E. \& Quattro, J.M. (1992) Analysis of molecular variance inferred from metric distances among DNA haplotypes: application to human mitochondrial DNA restriction data. Genetics 131, 479-491.

Excoffier, L., Laval, G. \& Schneider, S. (2005) Arlequin (version 3.0): an integrated software package for population genetics data analysis. Evol Bioinform Online 1, 47-50.

Gonzalez-Rodriguez, A., Benrey, B., Callejas, A. \& Oyama, K. (2002) Inter- and intraspecific genetic variation and differentiation in the sibling bean weevils Zabrotes subfasciatus and Z-sylvestris (Coleoptera: Bruchidae) from Mexico. Bulletin of Entomological Research 92, 185-189.

Grant, W.S. \& Bowen, B.W. (1998) Shallow population histories in deep evolutionary lineages of marine fishes: Insights from sardines and anchovies and lessons for conservation. Journal of Heredity 89, 415-426.

Guindon, S. \& Gascuel, O. (2003) A simple, fast, and accurate algorithm to estimate large phylogenies by maximum likelihood. Systematic Biology 52, 696-704.

Hall, T.A. (1999) BioEdit: a user-friendly biological sequence alignment editor and analysis program for Windows 95/98/ NT. Nucleic Acids Symposium Series 41, 95-98.

Hansson, C., Aebi, A. \& Benrey, B. (2004) Horismenus species (Hymenoptera: Eulophidae) in a bruchid beetle parasitoid guild, including the description of a new species. Zootaxa 548, $1-16$.

Hardy, O.J. \& Vekemans, X. (2002) SPAGEDi: a versatile computer program to analyse spatial genetic structure at the individual or population levels. Molecular Ecology Notes 2, 618-620.

Hilgenboecker, K., Hammerstein, P., Schlattmann, P., Telschow, A. \& Werren, J.H. (2008) How many species are infected with Wolbachia? A statistical analysis of current data. FEMS Microbiology Letters 281, 215-220.
Hurst, G.D.D., Jiggins, F.M., Von Der Schulenburg, J.H.G., Bertrand, D., West, S.A., Goriacheva, I.I., Zakharov, I.A., Werren, J.H., Stouthamer, R. \& Majerus, M.E.N. (1999) Male-killing Wolbachia in two species of insect. Proceedings of the Royal Society of London, Series B: Biological Sciences 266, 735-740.

Karlin, S. \& Nevo, E. (1986) Evolutionary Processes and Theory. Orlando, FL, USA, Academic Press.

Kwak, M. \& Gepts, P. (2009) Structure of genetic diversity in the two major gene pools of common bean (Phaseolus vulgaris L., Fabaceae). Theoretical and Applied Genetics 118, 979-992.

Kwak, M., Kami, J.A. \& Gepts, P. (2009) The putative Mesoamerican domestication center of Phaseolus vulgaris is located in the Lerma-Santiago Basin of Mexico. Crop Science 49, 554-563.

Lartillot, N., Lepage, T. \& Blanquart, S. (2009) PhyloBayes 3: a Bayesian software package for phylogenetic reconstruction and molecular dating. Bioinformatics 25, 2286-2288.

Legendre, P. \& Gallagher, E.D. (2001) Ecologically meaningful transformations for ordination of species data. Oecologia 129, 271-280.

Lozier, J.D., Roderick, G.K. \& Mills, N.J. (2007) Genetic evidence from mitochondrial, nuclear, and endosymbiont markers for the evolution of host plant associated species in the aphid genus hyalopterus (hemiptera: Aphididae). Evolution 61, 1353-1367.

Macfadyen, S. \& Bohan, D.A. (2010) Crop domestication and the disruption of species interactions. Basic and Applied Ecology 11, 116-125.

Nei, M. (1987) Molecular Evolutionary Genetics. New York, USA, Columbia University Press.

Nei, M. \& Tajima, F. (1981) DNA polymorphism detectable by restriction endonucleases. Genetics 97, 145-163.

Oksanen, J., Kindt, R., Legendre, P., O'hara, B., Simpson, G.L., Henry, M., Stevens, H.H. \& Wagner, H. (2008) Vegan: Community Ecology Package. R package version 1.13-1.

Orita, M., Iwahana, H., Kanazawa, H., Hayashi, K. \& Sekiya, T. (1989) Detection of polymorphisms of human DNA by gel electrophoresis as single-strand conformation polymorphisms. Proceedings of the National Academy of Sciences of the United States of America 86, 2766-2770.

Papa, R. \& Gepts, P. (2003) Asymmetry of gene flow and differential geographical structure of molecular diversity in wild and domesticated common bean (Phaseolus vulgaris L.) from Mesoamerica. Theoretical and Applied Genetics 106, 239250.

Posada, D. \& Crandall, K.A. (1998) Modeltest: testing the model of DNA substitution. Bioinformatics 14, 817-818.

Ramamoorthy, T.P. (1998) Diversidad Biológica de México: Orígenes y Distribución. México, UNAM.

Restoux, G., Hossaert-Mckey, M., Benrey, B. \& Alvarez, N. (2010) The effect of host plant and isolation on the genetic structure of phytophagous insects: A preliminary study on a bruchid beetle. European Journal of Entomology 107, 299-304.

Rigaud, T., Soutygrosset, C., Raimond, R., Mocquard, J.P. \& Juchault, P. (1991) Feminizing endocytobiosis in the terrestrial crustacean Armadillidium-Vulgare Latr (Isopoda) - recent acquisitions. Endocytobiosis and Cell Research 7, 259-273.

Romero, J. \& Johnson, C.D. (1999) Zabrotes sylvestris, a new species from the United States and Mexico related to Z-subfasciatus (Boheman) (Coleoptera: Bruchidae: Amblycerinae). Coleopterists Bulletin 53, 87-98.

Rossi, M., Bitocchi, E., Bellucci, E., Nanni, L., Rau, D., Attene, G. \& Papa, R. (2009) Linkage disequilibrium and population 
structure in wild and domesticated populations of Phaseolus vulgaris L. Evolutionary Applications 2, 504-522.

Sambrook, J. \& Russell, D.W. (2001) Appendix 8: commonly used techniques in molecular cloning. pp. AB.9-AB.10 in Sambrook, J. \& Russell, D.W. (Eds) Molecular Cloning: A Laboratory Manual. 3rd edn, Cold Spring Harbor, NY, USA, Cold Spring Harbor Laboratory Press.

Sheffield, V.C., Beck, J.S., Kwitek, A.E., Sandstrom, D.W. \& Stone, E.M. (1993) The sensitivity of single-strand conformation polymorphism analysis for the detection of single base substitutions. Genomics 16, 325-332.

Simon, C., Frati, F., Beckenbach, A., Crespi, B., Liu, H. \& Flook, P. (1994) Evolution, weighting, and phylogenetic utility of mitochondrial gene-sequences and a compilation of conserved polymerase chain-reaction primers. Annals of the Entomological Society of America 87, 651-701.

Smith, T.B. \& Wayne, R.K. (1996) Molecular Genetic Approaches in Conservation. New York, USA, Oxford University Press.

Stouthamer, R.\& Luck, R. (1993) Influence of microbe-associated parthenogenesis on the fecundity of Trichogramma deion and T. pretiosum. Entomologia Experimentalis et Applicata 67, 183-192.

Thompson, J.D., Gibson, T.J., Plewniak, F., Jeanmougin, F. \& Higgins, D.G. (1997) The CLUSTAL_X windows interface: flexible strategies for multiple sequence alignment aided by quality analysis tools. Nucleic Acids Research 25, 4876-4882.

Tscharntke, T. \& Hawkins, B.A. (2002) Multitrophic Level Interactions. Cambridge, UK, Cambridge University Press.

Tuda, M., Ronn, J., Buranapanichpan, S., Wasano, N. \& Arnqvist, G. (2006) Evolutionary diversification of the bean beetle genus Callosobruchus (Coleoptera: Bruchidae): traits associated with stored-product pest status. Molecular Ecology 15, 3541-3551.

Weir, B.S. \& Cockerham, C.C. (1984) Estimating F-statistics for the analysis of population structure. Evolution 38, 1371-1383.

Werren, J.H., Baldo, L. \& Clark, M.E. (2008) Wolbachia: master manipulators of invertebrate biology. Nature Reviews Microbiology 6, 741-751.

Yen, J.H. \& Barr, A.R. (1973) The etiological agent of cytoplasmic incompatibility in Culex pipiens. Journal of Invertebrate Pathology 22, 242-250.

Yu, M.Z., Zhang, K.J., Xue, X.F. \& Hong, X.Y. (2011) Effects of Wolbachia on mtDNA variation and evolution in natural populations of Tetranychus urticae Koch. Insect Molecular Biology 20, 311-321.

Zizumbo-Villarreal, D., Colunga-Garciamarin, P., Payro De La Cruz, E., Delgado-Valerio, P. \& Gepts, P. (2005) Population structure and evolutionary dynamics of wild-weedy-domesticated complexes of common bean in a Mesoamerican region. Crop Science 45, 1073-1083. 